\title{
Manual therapy in diaphragm muscle: effect on respiratory muscle strength and chest mobility
}

\author{
Darling Kescia Araújo Peixoto Braga', Débora Fortes Marizeiro', Ana Carolina Lins Florêncio', Mariana Dias Teles', \\ Ítalo Caldas Silva', Francisco Fleury Uchôa Santos-Júnior ${ }^{2,3}$, Nataly Gurgel Campos
}

\begin{abstract}
Introduction: Manual therapy uses the hands as a form of healing, being a manipulation for therapeutic purposes. However, there is little evidence of its effects on the respiratory system. Objective: To describe the effect of manual therapy on the diaphragm, on respiratory muscle strength and on the mobility of the thoracic cavity. Method: Descriptive, longitudinal, interventional and quantitative research, performed at the Cardiopneumofunctional Physical Therapy Laboratory of the Federal University of Ceará (UFC). The sample consisted of 40 sedentary female students, aged between 18 and 35 years of the Physiotherapy course of the UFC. The following techniques were performed: "diaphragm lift" and double diaphragm. Data collection was performed in three steps, on the same day and by the same researcher, under a homogeneous verbal command. It was considered statistically significant value of $p \leq 0,05$. Results: After applying the techniques, a comparative analysis was performed, which demonstrated a statistically significant difference in the maximum expiratory pressure, with $p<0,0001$, and all the coefficients of the cirtometry, being $p<0,0025$ (axillary), $p<0,0085$ (xiphoid) and $p<0,0005$ (basal). Conclusion: Manual therapy techniques performed on the diaphragm exert an influence on muscle strength due to the increase in maximum expiratory pressure and in the mobility of the thoracic cavity, reflected in the increase of the coefficients of the cirtometry.

Keywords: Musculoskeletal Manipulations, Diaphragm, Muscle Strength, Thorax.
\end{abstract}

\section{INTRODUCTION}

The respiratory system is an airway system, attached to a pair of lungs, which are covered by a fibrous tissue membrane (pulmonary pleura), being directly connected to the circulatory system in the process of gas exchange, oxygenating the tissues of the body. ${ }^{(1)}$ This function is performed in a coordinated and rhythmic manner with the contribution of various expiratory and inspiratory muscles, and among them the diaphragm is considered the most important. ${ }^{(2)}$ These muscles are known as respiratory and are directly responsible for the proper functioning of pulmonary ventilation, making a pump system as vital as the heart. ${ }^{(3)}$

The pressures generated in the respiratory system depend on the forces generated during muscle contraction and on the elastic properties of the lung and chest wall. ${ }^{(4)}$

The diaphragm is the main muscle of respiration, and if it is shortened it can alter both its contraction force and lung volumes and capacities, since lung volume can be considered as the length index of the respiratory muscle. Therefore, improvement of muscle length may be influenced by both manual therapy (MT) techniques and techniques and features that promote volumetric variations..$^{(5)}$

MT uses the hands as a form of healing, a manipulation for therapeutic purposes that ultimately influences the ability to repair, in which changes can occur both at the level of local repair and in the general behavior of the individual. ${ }^{(6)}$ Despite the benefits of using MT in the respiratory system, works with this approach are rare. ${ }^{(7)}$

Osteopaths, chiropractors and manual therapists are trained to perform manipulations and adjustments in the body, and these techniques can mobilize joints, improve range of motion, relax muscles and reduce muscle pain ${ }^{(8)}$. The techniques of manipulation and musculoskeletal mobilization are part of a set of maneuvers that belong to a collection of the practice of MT, which in Brazil is practiced by physiotherapists. ${ }^{(9,10)}$

Considering the number of researches that relate manual physiotherapy as a way of assisting the respiratory physiotherapy conducts, the aim of this research was to

Corresponding author: Name: Darling Kescia Araújo Peixoto Braga Address: Tibúrcio Rodrigues, 100, Cond. Sta. Barbara, Apto. 402, Bl. 02 Telephone: +55 (85) 9673-

5909 E-mail: darlingkescia@yahoo.com.br

1 Universidade Federal do Ceará (UFC), Fortaleza (CE), Brazil

Full list of author information is available at the end of the article.

Financial support: The authors declare they financed this study.

Submission date 02 August 2016; Acceptance date 29 October 2016; Publication online date 10 November 2016 
describe the effect of manual therapy on the diaphragm, on respiratory muscle strength and on the mobility of the thoracic cavity.

\section{METHODS}

Descriptive, longitudinal, interventional and quantitative study, performed at the Cardiopneumofunctional Physical Therapy Laboratory of the Federal University of Ceará (UFC), of Physiotherapy course of the Federal University of Ceará (UFC), located at the following address: Rua Alexandre Baraúna, 949, Rodolfo Teófilo, Fortaleza - Ce. The collection period was from August to September 2014.

The sample included 40 students from the Physiotherapy course of the UFC, being for convenience and non-probabilistic, including only sedentary female students and aged between 18 and 35 years. All signed the Informed Consent Term (TCLE). This research was part of the project called "The influence of manual therapy on diaphragmatic function", approved by the Research Ethics Committee of César Cals General Hospital in 2011, according to protocol number 047/2011. Exclusion criteria were those with cardiovascular disease, obstructive or restrictive respiratory disease, smokers and ex-smokers, who are or were submitted to speech therapy and those who participated or participate in a singing group.

The survey was conducted in three stages: 1) Initially, the participants were submitted to the manovacuometry and cirtometry tests to evaluate respiratory muscle strength and chest cavity mobility, respectively; 2 ) Then two manual therapy techniques were performed on the diaphragm ("lift diaphragm" technique and relaxation technique for the diaphragm); 3) Finally, the participants were re-evaluated in the same initial tests. All three steps were performed on the same day, by the same researcher, under homogeneous verbal command.

The manovacuometry was performed with the $M R^{\circledR}$ analogue manovacuometer brand, in the orthostatic position, which offers the greatest mechanical advantage to the respiratory muscles, and it is believed that in this position the abdominal contents do not interfere with the diaphragmatic displacement, generating a greater intrathoracic volume ${ }^{(11)}$.

Thus, as we aimed to apply techniques of manual therapy on the diaphragm, would be required a posture in which it moved in its greatest amplitude and that is the case of orthostatic. To measure maximal inspiratory pressure (IPmáx) an expiration of residual volume (RV) level was requested, followed by rapid and strong inspiration at the level of total lung capacity (TLC), with verbal stimulus of the examiner. For the maximum expiratory pressure (EPmáx) a maximum inspiration was requested at the level of TLC followed by a maximal expiration up to the RV level, with verbal stimulus of the examiner. Each request was made three times, opting for the best result of the three.
After the manovacuometry, we performed the cirtometry exam, which aims to quantify the measures of thoraco-abdominal mobility and provides the coefficients of axillary amplitude (CA-Ax), xiphoid (CA-Xif) and basal (CA-Ba). Measurements of these values were done with a simple "Fiber-Glass" measuring tape, staggered in centimeters, around the patient's chest and/or abdomen, requiring a maximum inspiration and expiration. The difference between the measurements obtained at maximal inspiration and expiration at each anatomical level was considered as the thoraco-abdominal mobility of each measured region. Measurements were performed three times at each level, using the highest value measure. ${ }^{(12)}$

The first technique was the "lift diaphragm", which has the purpose of generating the stretching of the peripheral fibers of the diaphragm, being performed with the patient in the supine position and the therapist standing above the patient's head, holding the lower edge with the tip of the fingers curved. The therapist requests that the patient adapt a slightly amplified breathing and, during the inspiration phases, exerts a cephalic traction. In the phases of expiration, she maintains this traction without increasing it, and so on, until the perception of no longer being able to pull the tissues. Then they were asked for an exhale apnea and a contraction of his belly. At the end of the apnea, he gently relaxes the costal arch. The technique is performed twice on each side. ${ }^{(13)}$

The second technique was the relaxation of the diaphragm, which aims to promote the rhythmic stretching of the double pairs of the diaphragm, being performed with the patient in the prone position and the therapist standing beside her placing the ulnar border of her cephalic hand in relation to the transverse ones and its caudal hand flattened in front of the popliteal fossa. Respecting the patient's breathing rhythm, the therapist makes a divergent support by dropping the weight of his body on his two hands, which will move away without slipping, during the exhalation phase and relaxing that pressure in the inspiration phase. This maneuver was performed for one minute on each side. ${ }^{(13)}$

For the data collection, an evaluation form was applied according to the purposes of the study, elaborated by the researchers, containing the following variables: age, weight, height, body mass index (BMI), the manovacuometry data (IPmáx and EPmáx pre-therapy; IPmáx and EPmáx post-therapy) and those of cirtometry (CA-Ax, CA-Xif and CA-Ba pre-therapy; CA-Ax, CA-Xif and CA-Ba post-therapy).

To compare the Manovacuometry and Cirtometry before and after the application of the techniques, the paired Student's t-test was used, with the aid of the statistical program GraphPad Prism 6.0. Data were expressed as means \pm standard deviation. It was considered statistically significant the value of $p \leq 0,05$. 


\section{RESULTS}

The following data are presented for the characterization of the sample. The mean age was $22,35 \pm 2,95$ years, weight of $59,89 \pm 9,29 \mathrm{Kg}$, height of 1,62 $\pm 0,54$ meters and BMI of $22,75 \pm 3,21 \mathrm{Kg} / \mathrm{m}^{2}$. The Ministry of Health considers "healthy weight" people with a BMI between 18-25 and "overweight" people with a BMI greater than 25. ${ }^{(14)}$ (Table 1 ).

\section{Assessment of maximum respiratory pressures}

When analyzed the IPMax pre and post the therapies utilized was observed that the pre IPMax obtained an average of $90,02 \pm 15,10 \mathrm{~cm} / \mathrm{H}_{2}$ Oe and post IPMax obtained an average of $94,05 \pm 24,40 \mathrm{~cm} / \mathrm{H}_{2} \mathrm{O}(\mathrm{p}=0,1693)$, presenting no difference between the evaluations (Figure 1-A). When analyzed the EPMax pre and post the techniques of MT was observed that the pre EPMax obtained an average of $65,05 \pm 20,29 \mathrm{~cm} / \mathrm{H}_{2} \mathrm{O}$ and after the treatment this value increased about $14 \%$ $\left(74,25 \pm 19,08 \mathrm{~cm} / \mathrm{H}_{2} 0 ; \mathrm{p}<0,0001\right)$ (Figure 1-B).

\section{Analysis of thoracic mobility}

When analyzed the CA-Ax pre and post the used therapies, was observed an increase $(p<0,0025)$ in the final value $(6,93 \pm 1,81 \mathrm{~cm})$ in relation to the initial value $(6,17 \pm 1,66 \mathrm{~cm})$ (Figure 2A). In the evaluation of CA-Xif was evidenced that CA-Xif also had an increase $(p<0,0085)$ in the final value $(6,63$ $\pm 2,48 \mathrm{~cm})$ in relation to the value $(5,85 \pm 2,20 \mathrm{~cm}$ ) before the techniques of $\mathrm{MT}$ (Figure $2 \mathrm{~B}$ ). In the CA-Ba analysis there was also an increase $(p<0,0005)$ in final mobility $(6,16 \pm 1,73 \mathrm{~cm})$ in relation to the initial condition $(5,41 \pm 2,03 \mathrm{~cm}$ ) (Figure $2 \mathrm{C}$ ).

\section{DISCUSSION}

In the present study only one of the variables that represent respiratory muscle strength, EP Max, suffered statistically significant changes. The IP Max variable had its results improved, but it was not statistically significant.

When comparing these results with the literature, it was observed a divergence regarding the values of IP Max after the techniques. In a clinical trial ${ }^{(15)}$ with 43 volunteers, whose objective was to evaluate the immediate effect of the application of two manual therapy techniques on maximal inspiratory pressure (IP Max) in healthy individuals, individually applied or associated, it was observed that there was no statistical difference in the IP Max variable, but an

Table 1. Presentation of the mean values and standard deviation of age. weight. height and BMI of the study participants. Fortaleza/CE. 2014.

\begin{tabular}{lcccc}
\hline & Age (years) & Weight $(\mathrm{kg})$ & $\begin{array}{c}\text { Height } \\
\text { (metros) }\end{array}$ & BMI (Kg/m²) \\
\hline $\begin{array}{l}\text { Mean } \\
\begin{array}{l}\text { Standard } \\
\text { error }\end{array}\end{array}$ & 22.35 & 59.89 & 1.62 & 22.75 \\
\hline
\end{tabular}

$\mathrm{BMI}=$ Body mass index. $\mathrm{N}=40$ evaluated improvement of inspiratory strength after application of the techniques, corroborating with our findings. It is important to point out that the interventions consisted of two manual therapy techniques, one manipulative and the other for diaphragm mobilization, similar to the "diaphragm lift" technique performed in the present study.

Still in relation to the pressures, a previous study (16) ${ }^{a}$ nalyzed the effect of diaphragmatic release on respiratory pressures in healthy and sedentary young, with 20 volunteers, showing that the values obtained at maximum respiratory pressures were statistically significant. In this case, this study shows only consistent with our research regarding the EPmax.

Thus, it is suggested that the difference in the intervention protocols may have contributed to these results. In addition, it is believed that the execution time and the amount of load applied are directly linked to the effect of the techniques.

With regard to cirtometry, the present study showed that there was an increase in the thoracic mobility in the three regions measured, which promoted increases in thoracic
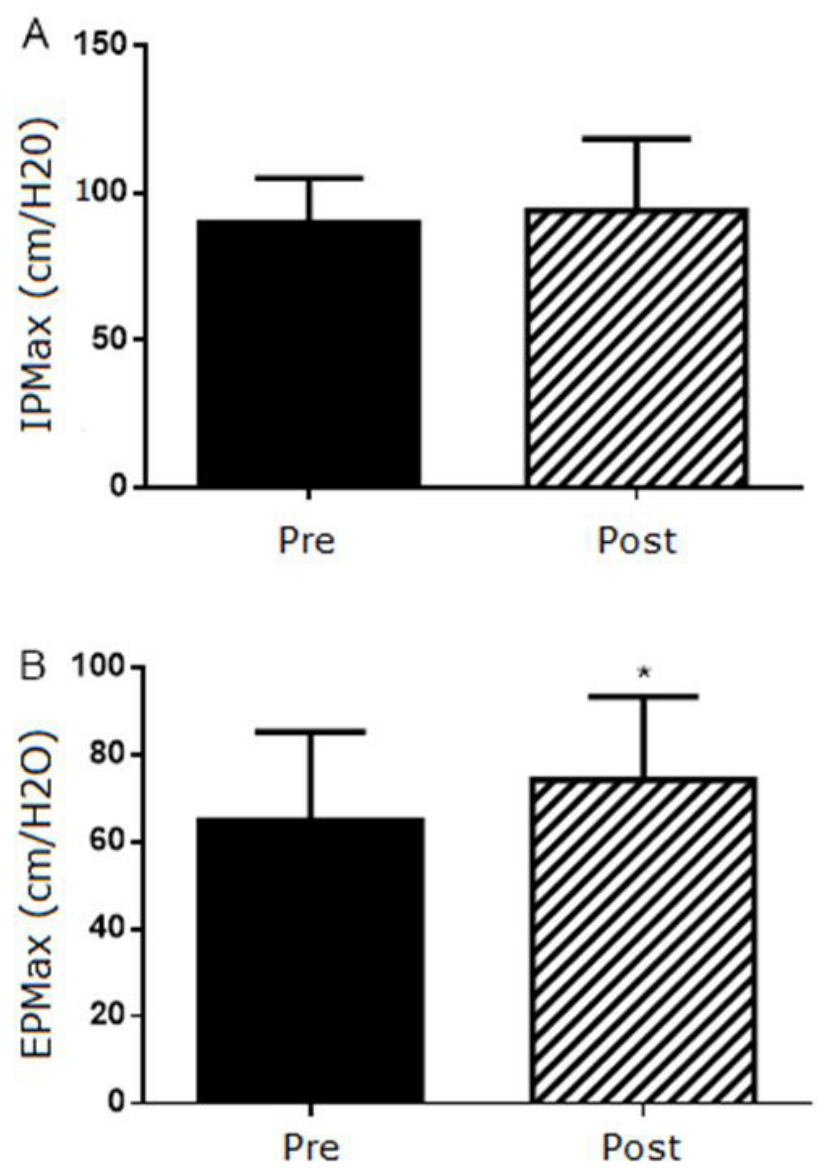

Figure 1. Analysis of maximum respiratory pressures A - Comparison of IP Max (Maximum Inspiratory Pressure) before and after the application of manual therapy techniques. B - Comparison of EP Max (Maximum Expiratory Pressure) before and after the application of manual therapy techniques. Paired Student t test. Fortaleza/Ce, 2014. *Statistical difference. 

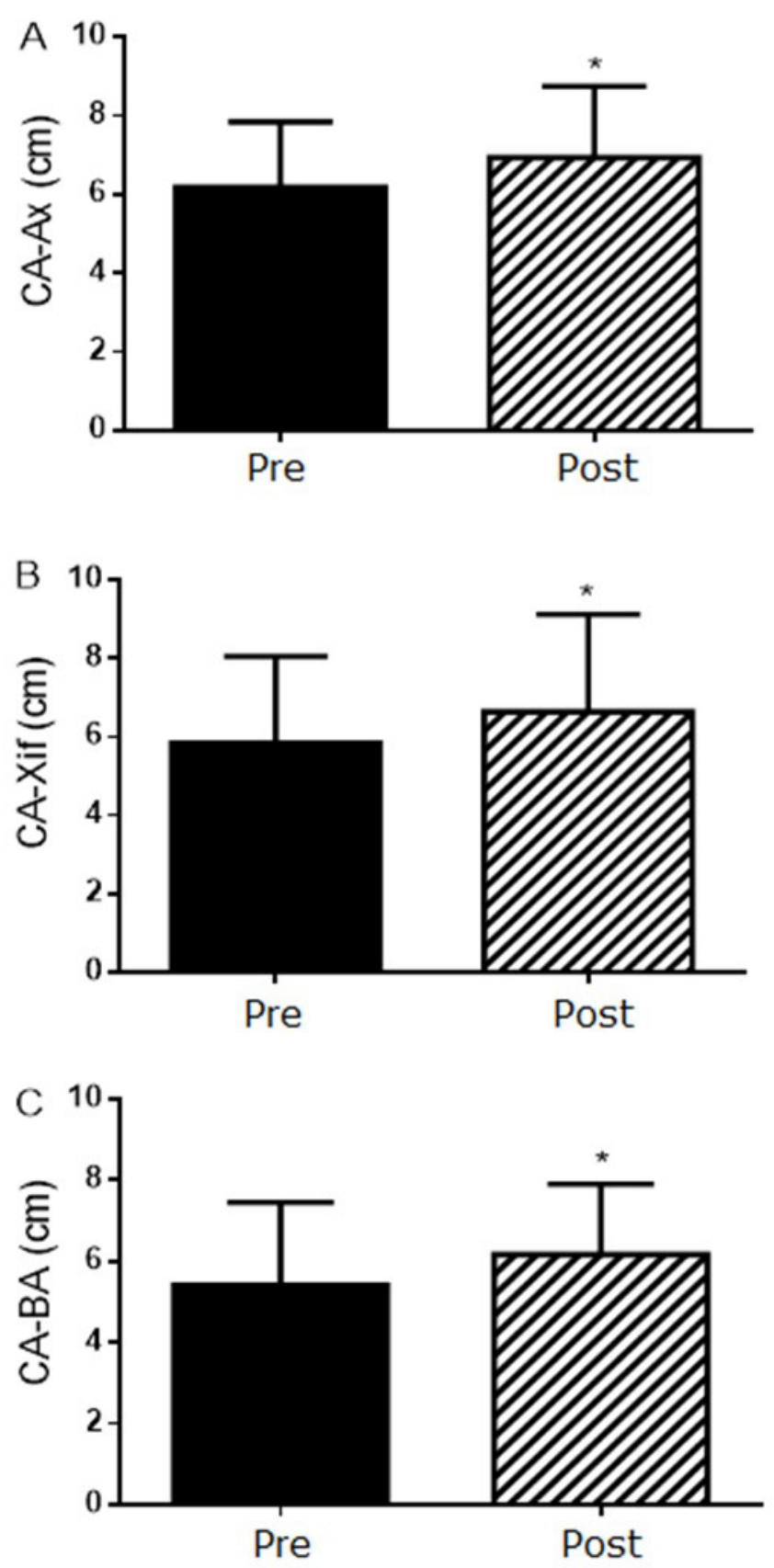

Figure 2. Analysis of thoracic mobility. A - Comparison of CA-Ax (Axillary Amplitude Coefficient) before and after the application of techniques of manual therapy. B - Comparison of CA-Xif (Xiphoid Amplitude Coefficient) after the application of techniques of manual therapy. C - Comparison of CA-Ba (Basal Amplitude Coefficient) after the application of techniques of manual therapy. Paired Student t test. Fortaleza/Ce, 2014. *Statistical difference.

cavity expansion, providing a better performance of global respiratory mechanics.

These results obtained in cirtometry agree with the data obtained by a study ${ }^{(17)}$ which wished to compare the influence of the diaphragmatic myofascial release technique and the respiratory stimulator in normal individuals, with 20 participants, thus confirming a significant increase in apical, xiphoid and abdominal expansion.
Still on the results obtained in cirtometry, a research ${ }^{(18)}$ evaluated the effect of a muscle stretching program using the Global Postural Reeducation (CPR) on respiratory muscle strength and thoracoabdominal mobility in 20 volunteers, showing a significant increase in measurements of thoracicabdominal cirtometry. The present study did not use postural treatment of CPR, but the protocol of intervention used by them was constituted of a program of stretching of the respiratory muscle chain, thus involving the diaphragm.

In agreement with the aforementioned studies, the results of this research also demonstrated a significant increase of all thoracic-abdominal amplitude coefficients. This was probably due to the fact that the techniques provided an increase in the flexibility of the respiratory muscles and the thoracic cavity, as well as an improvement in the length-tension relationship, allowing a beneficial effect on the performance of respiratory mechanics.

Manual therapy aims to stimulate proprioception, increase the elasticity of adhered fibers, stimulate synovial fluid and reduce pain. Fascial release has its efficacy based on the elimination of tension in the soft tissues, trigger points and muscle defense status, through low speed movements, which when applied over the area, act on the sensory system through the Golgi tendon organs ${ }^{(19)}$.

However, there is little research that gives scientific support to the effects of such techniques. In the literature there is a deficiency of studies on the action of stretching of the respiratory muscles, affirming to us that this probably occurs because it is a muscular group of complex functioning and, perhaps for this reason, does not present specific techniques. ${ }^{(18)}$ The results of our study demonstrate that the manual techniques performed in the diaphragm exert a positive influence on respiratory muscle strength and thoracoabdominal mobility.

The limitations of the present study are related to the fact that it was performed only with healthy individuals, in spite of the results achieved indicating the benefits of the manual techniques used for diaphragmatic muscle strength and thoracic mobility, a direct relationship cannot be established between the experimental condition and the clinical conditions involving patients. Beyond this, another limiting factor lies in the fact that the methodological proposal of intervention was unique.

Given the scarcity of studies in this area, comparison with other similar studies was not efficient. Thus, it is important to emphasize the approach given in the present study by employing manual therapy, a therapeutic method that still requires scientific validation of what is reported in clinical practice, especially regarding its use in the respiratory muscles.

Therefore, it is suggested that additional studies with this theme should be performed with a larger number of volunteers, both healthy and with respiratory dysfunctions, in order to broaden the rationale of evidence-based Physiotherapy. 


\section{CONCLUSION}

In the assessment of pulmonary function after intervention, there was an improvement in EPmax values, suggesting that Manual Therapy improves expiratory efficiency by promoting an increase in the expiratory muscle strength or by the increase of the thoracic cavity expansion, a fact also observed in this study.

\section{AUTHOR'S CONTRIBUTION}

DKAPB: writing, functional respiratory protocols, mechanical respiratory protocols DFM: manual therapy intervention, ACLF: functional respiratory protocols, MDT: mechanical respiratory protocols ICS: mechanical respiratory protocols; FFUSJ: study design, writing, statistical analysis; NGC: study design, writing, protocols supervision.

\section{CONFLICTS OF INTEREST}

The author(s) declare that they have no competing interests.

\section{AUTHOR DETAILS}

${ }^{2}$ Faculdade Maurício de Nassau, Fortaleza (CE), Brazil

${ }^{3}$ Centro Universitário Estácio do Ceará, Fortaleza(CE), Brazil.

\section{REFERENCES}

1. Costa D. Fisioterapia respiratória básica. São Paulo: Atheneu, 2004.

2. Dalley AF, Moore KL. Anatomia orientada para clínica. 4 ed. Rio de Janeiro: Guanabara Koogan, 2001.

3. Azeredo CAC. Fisioterapia respiratória moderna. 4a ed. São Paulo: Manole; 2002.

4. Irwin S, Tecklin JS. Fisioterapia Cardiopulmonar. 2 ed. São Paulo: Manole, 1994.

5. Oliveira J.B.B, Freitas C.H. Fisioterapia pneumofuncional: perguntas e respostas. Fortaleza: Unifor; 2002.

6. Lederman E. Fundamentos da Terapia Manual. São Paulo: Manole, 2001.
7. Bertholdi EMG, Vanderlinde F, Silva FL, Matsui JMK, Nienkoetter JM, Rosa $\mathrm{GJ}$, Santos CIS. Recursos e técnicas de terapia manual no tratamento de doenças respiratórias: existe comprovação? Ter. Man. 2010;8(S1):241-245.

8. Chaitow L. Síndrome da fibromialgia: um guia para o tratamento. São Paulo: Manole, 2002.

9. Mccarthy CJ. Spinal manipulative thrust technique using combined movement theory. Man. Ther. 2001;6(4):197-204.

10. Bolton PS, Budgell BS. Spinal manipulation and spinal mobilization influence diferente axial sensory beds. Med. Hypotheses. 2006;66:258262.

11. Costa GM, Lima JGM, Lopes AJ. Influência da postura e do clipe nasal na espirometria. Pulmão. 2006;15(3):143-147.

12. Pedrini A, Gonçalves MA, Leal BE, Yamaguti WPS, Paulin E. Comparação entre as medidas de cirtometria tóraco-abdominal realizadas em decúbito dorsal e em ortostatismo. Fisioter Pesq. 2013;20(4):373-378.

13. Quef BH. Técnicas osteopáticas viscerais. São Paulo: Livraria Santos Editora, 2008.

14. Passarinho, N. Quase metade da população está acima do peso, diz Saúde. 2010. Acesso em: 23 jul 2014.

15. Carvalho AR, Silva SL, Oliveira AP. Efeito imediato de duas técnicas de terapia manual sobre a pressão inspiratória máxima em indivíduos saudáveis: ensaio clínico. Ter. Man. 2011;9(42):143-149.

16. Novaes PA, Sanchez EGM, Sanchez HM. Medida das pressões respiratórias máximas em jovens saudáveis antes e após manobra de liberação diafragmática. Revista Inspirar Movimento \& Saúde. 2013;5(2):1-5.

17. Vasconcelos SS, Viana NSP, Mont'Alverne DGB, Freitas IMP, Gouveia SSV, Gouveia GPM. Estudo comparativo entre a técnica de liberação diafragmática e o uso de incentivador respiratório em indivíduos normais. Ter. Man. 2011;9(46):457-463

18. Moreno MA, Catai AM, Teodori RM, Borges BLA, Cesar MC, Silva E. Efeito de um programa de alongamento muscular pelo método de Reeducação Postural Global sobre a força muscular respiratória e a mobilidade toracoabdominal de homens jovens sedentários. J. Bras. Pneumol. 2007;33(6):679-686.

19. Andrade TNC, Frare JC. Estudo comparativo entre os efeitos de técnicas de terapia manual isoladas e associadas à laserterapia de baixa potência sobre a dor em pacientes com disfunção temporomandibular. RGO, Porto Alegre. 2008;56(3):287-295. 